Volume 10 Issue 1 (2021) Pages 1-8

\title{
Ta'dib: Jurnal Pendidikan Islam
}

ISSN: 2528-5092 (Online) 1411-8173 (Print)

https://ejournal.unisba.ac.id/index.php/tadib/article/view/6999

\section{ECOLOGICAL VALUE OF KECAP PAMALI IN THE COMMUNITY OF KAMPUNG NAGA, TASIKMALAYA REGENCY}

\author{
Asep Deni Gustiana ${ }^{1}$, Mamat Supriatna ${ }^{2}$ \\ Universitas Pendidikan Indonesia ${ }^{1,2}$ \\ Email: asden@upi.edu ${ }^{1}$, ma2t.supri@upi.edu ${ }^{2}$ \\ DOI: https://doi.org/10.29313/tjpi.v10i1.6999 \\ Received: December 06th, 2020. Accepted: May 1th, 2021. Published: May 1th, 2021.
}

\begin{abstract}
People currently live in a modern and technological era, as a result, the local wisdom of an area is starting to erode. Even though there are many values contained in local wisdom that can be adopted and applied in an educational process. This article aims to describe comprehensively the results of the analysis of pamali soy sauce in the perspective of the people of Kampung Naga. In addition, this article discusses the ecological value contained in kecap pamali and the possibility of its culture in elementary school education. The method used is literature review and field study in the form of interviews and observations. The observations were made to see the behavior of the people of Kampung Naga related to kecap pamali.
\end{abstract}

Keywords: Kecap Pamali; Ekological Value; Elementary School Students.

\begin{abstract}
Abstrak
Masyarakat saat ini bidup dalam jaman yang modern dan serba teknologi, imbasnya kearifan local suatu daerah mulai tergerus. Padahal banyak sekali nilai-nilai yang terkandung dalam kearifan local tersebut yang dapat diadopsi dan ditearpkan dalam suatu proses Pendidikan. Artikel ini bertujuan untuk mendeskripsikean secara komprehensif tentang hasil analisis kecap pamali dalam pandangan masyarakat Kampung Naga. Selain itu artikel ini membahas tentang Nilai Ekologis yang terdapat dalam kecap pamali serta kemungkinan enkulturasinya dalam pendidikan Sekolah Dasar. Metode yang digunakan adalah kajian pustaka dan studi lapangan dalam bentuk wawancara dan observasi. Adapun observasi dilakukan untuk melihat perilaku masyarakat Kampung Naga berkaitan dengan kecap pamali. Nilai guna dari kajian ini berupa pandangan kecap pamali masyarakat Kampung Naga yang dapat dijadikan landasan dalam Penguatan Nilai Ekologis Siswa Sekolah Dasar.
\end{abstract}

Kata Kunci: Kecap Pamali; Nilai Ekologis; Siswa Sekolah Dasar. 


\section{PENDAHULUAN}

Kampung Naga merupakan sebuah wilayah yang dihuni oleh sekelompok warga yang masih memegang kuat adat istiadat leluhurnya. Wilayahnya terletak di Desa Neglasari Kecamatan Salawu Kabupaten Tasikmalaya. Terdapat beberapa versi tentang karuhun dari masyarakat Kampung Naga, namun dari semua versi tersebut dapat diambil kesimpulan bahwa Eyang Singaparna merupakan karuhun dari warga Kampung Naga (Qodariah, 2013; Suryani \& Charliyan, 2010).

Masyarakat Kampung Naga memiliki karifan local (local wisdom) dalam kehidupan bermasyarakatnya. Kearifan dapat dipahami sebagai gagasan-gagasan yang berasal dari suatu wilayah setempat yang bernilai baik, bersifat bijaksana dan diikuti oleh anggota masyarakatnya (Qodariah, 2013) serta dimaknai sebagai pemikiran hidup (Nurdiansah, 2017). Lebih lanjut Rosidi dalam (As'ari \& Hendriawan, 2016) mengatakan bahwa kearifan merupakan kemampuan kebudayaan masyarakat setempat dalam menyikapi kebudayaan asing yang datang.

Salah satu kearifan dari masyarakat Kampung Naga yakni adanya pantangan (tabu). Menurut beberapa ahli tabu merupakan suatu nilai budaya dari adat istiadat yang berupa larangan terhadap sesuatu hal, dengan dikenakan sanksi sosial bagi pelanggarnya (Barus, 2020; Hasnidar \& Erdian, 2019). Adapun ungkapan tabu di suku Sunda dalam hal ini masyarakat Kampung Naga lebih dikenal dengan "Kecap Pamali” (ungkapan/istilah pamali) (Rachmawati, 2017).

Sembah Dalem Singaparna merupakan leluhur Kampung Naga yang telah memberikan petuah berupa Kecap pamali yang perlu diyakini serta ditaati dengan penuh kesungguhan oleh masyarakat setempat agar senantiasa mendapatkan keselamatan serta ketenangan jiwa selama hidup bermasyarakat. Tak hanya itu, Kecap pamali dijadikan pegangan hidup bagi masyarakat Kampung Naga dalam menjalani kehidupan bermasyarakat. Pada dasarnya, nilai-nilai pamali dapat dijadikan suatu banteng yang dapat melindungi diri dari kemungkinan gangguan yang ditimbulkan oleh perkembangan modernisasi (As'ari \& Hendriawan, 2016). Hal tersebut diaplikasikan oleh warga Kampung Naga yang sangat menghormati para leluhurnya dengan masih taat menjalankan adat istiadat nenek moyang. Masyarakat Kampung Naga menyakini bahwa segala sesuatu yang tidak dilakukan oleh leluhurnya dan sesuatu yang datang bukan dari ajaran leluhurnya, maka hal tersebut dianggap sebagai sesuatu yang pamali/tabu.

Apabila hal-hal yang dilarang tersebut dilakukan oleh masyarakat Kampung Naga berarti tidak menghormati karuhun dan melanggar adat, hal ini menurut mereka akan menimbulkan malapetaka. Begitu kuatnya kecap pamali dalam mempengaruhi 
kehidupan masyarakat Kampung Naga (Rachmawati, 2017), sehingga membuat penulis tertarik untuk menelitinya lebih dalam lagi.

Kecap "pamali" berasal dari suku kata "pa" dan "mali" . Pa- maknanya alat yang dipakai untuk membalikan, maksudnya segala sesuatu yang harus dipantang karena pamali kelak tidak akan dipantang oleh orang yang sudah malik (berbalik hatinya). Makanya ada peribahasa sunda "kudu inget ka bali geusan ngajadi" artinya kembali kepada kuadrat tempat asal semula. Kata "mali" dalam bahasa sunda "bali" artinya balik atau malik (berbalik) (Mustapa, 2010).

Kecap Pamali merupakan suatu legitimasi kata yang berisi larangan-larangan bagi masyarakat Kampung Naga yang dipahami serta ditaati secara turun temurun sebagai kesadaran social yang tulus, tanpa ancaman serta tanpa sanksi yang tertulis. Legitimasi larangan tersebut memuat makna sebagai suatu hal yang bersifat tabu serta magis yang tidak boleh dipertanyakan. Pamali ini memuat makna larangan sekaligus makna sanksi yang tidak bisa diukur batasannya (Nurdiansah, 2017).

Kata pamali secara bahasa berarti pantangan. Namun, secara istilah pamali dijelaskan sebagai sebuah pantangan dari suatu hal berdasarkan tradisi atau budaya yang dilarang dilakukan karena akan mendatangkan malapetaka atau faktor tidak baik untuk pelanggar atau orang yang didekatnya (Khomaeny dkk., 2020).
Dengan demikian pamali merupakan larangan karuhun berdasarkan tradisi, yang akan menimbulkan malapetaka apabila dilanggar (Satjadibrata, 1948; Danadibrata, 2006; Apiyanti et al., 2015; Widiastuti, 2015; As'ari \& Hendriawan, 2016; Rachmawati, 2017).

Bentuk pamali yang ada di masyarakat Kampung Naga terdiri dari ucapan, tindakan, dan benda. Pamali ucapan contohnya menyebut sembah Dalam Singaparna hanya Namanya saja, sedangkan pamali benda contohnya rumah bertembok, atap menggunakan genting/daun kiray, serta pintu kori (dua daun) (As'ari \& Hendriawan, 2016). Contoh pamali tindakan 1) Pamali masuk kedalam hutan larangan, 2) Pamali menebang pohon di hutan larangan 3) Pamali jika sudah menebang pohon tetapi tidak ditanami lagi 4) Pamali jika mengambil ikan menggunakan racun serta menggunakan "setrum" listrik 5) Pamali jika menanam dan memanen bukan di bulannya 6) Pamali jika memanen di hari “apes” (Nurdiansah, 2017).

Tokoh-tokoh yang memegang peranan penting pada adat istiadat kecap pamali di masyarakat Kampung Naga meliputi Kuncen/Ketua Adat, Punduh Adat, Lebe Adat, dan perwakilan anggota masyarakat Kampung Naga yang paling tua dan paling muda (As'ari \& Hendriawan, 2016).

Adapun ruang dari penggunaan kecap pamali yakni di lingkungan keluarga, tempat keramat, hutan, dan lingkungan sekitar Kampung Naga. Waktu pengungkapannya 
tidak terbatas, yakni ketika ada orang mendekati atau melakukan sesuatu yang dianggap pantangan.

Kecap pamali diungkapkan ketika ada orang lain akan melanggar sesuatu hal yang dilarang berdasarkan budaya atau tradisi setempat (Permasih et al., 2014). Jadi kecap pamili terucap ketika ada orang, baik dari masyarakat Kampung Naga maupun dari luar, ketika akan melakukan sesuatu yang dilarang atau ditabukan oleh tradisi setempat dalam lingkungan Kampung Naga.

Nilai adalah sesuatu yang dipandang baik (tingkah laku, keindahan, kebenaran, keadilan dan efisiensi) yang mengikat dan diyakini oleh seseorang atau sekelompok orang (Febriana, 2019; Syafiuddin, 2020; Supriatna, 2020 Ed.). Lebih lanjut Supriatna mengungkapkan bahwa ekologis merupakan suatu hubungan timbal balik yang berlangsung antara makhluk hidup dengan lingkungan sekitarnya.

Dengan demikian nilai ekologis merupak sesuatu yang dipandang baik dan bersifat hubungan timbal balik antara manusia dengan lingkungan di sekitarnya

\section{METODE PENELITIAN}

Metode penelitian yang digunakan adalah etnografi. Etnografi merupakan usaha peneliti menguraikan suatu kebudayaan atau aspek-aspek kebudayaan (Moleong, 2002). Fokus penelitian ini adalah kecap pamali, sedangkan objek atau variable penelitiannya adalah nilai ekologis. Untuk mengetahui nilai ekologis yang terdapat dalam kecap pamali maka dipalukan wawancaran terkait bentuk, luang, ruang dan kegiatan dari kecap pamali. Adapun yang menjadi sumber wawancara yakni Kuncen (ketua adat), Punduh adat, punduh Desa, Lebe adat, dan perwakilan dari masyarakat Kampung Naga dengan kriteria termuda dan tertua.

\section{HASIL DAN PEMBAHASAN}

Dari hasil penelitian yang dilakukan peneliti di Masyarakat Kampung Naga, diperoleh data terkait kecap pamali sebagai berikut.

Pamali merupakan larangan dari karuhun yang turun temurun dan diyakini oleh masyarakat Kampung Naga. Seperti hasil wawancara dengan Bapak Maun selaku punduh adat pada hari Jum'at tanggal 13 November 2020 diperoleh informasi bahwa asal usul kecap pamali tidak jelas awalnya karena bukti-bukti sejarah terbakar pada saat terjadi pemberontakan DII/TII, yang pasti berasal dari karuhun yang diwariskan turun temurun.

Lebih lanjut Punduh Adat mengatakan tentang pengertian kecap pamali adalah larangan dari karuhun yang tidak bisa ditawar lagi. Selain itu, beliau meyakini dibalik kecap pamali orang tua dahulu ada makna yang terkandung dari ungkapan tersebut.

Wawancara kedua dilakukan dengan Bapak Otoy selaku perwakilan warga masyarakat yang dituakan, beliau mengatakan 
bahwa kecap pamali sudah ada sejak orang tua dahulu yang tidak bisa di tawar-tawar lagi.

Hasil wawancara dengan Punduh Adat pada hari yang sama, bahwa banyak jenis-jenis pamali, namun yang utama adalah pamali asup ka leweng Karamat jeng larangan (masuk ke hutan keramat dan larangan) dan moto Bumi Ageung (istilah rumah untuk menyimpan benda-benda pusaka), komo nepi ka asup mah (mengambil poto Bumi Ageung, apalagi sampai masuk). Lebih lanjut, Kecap pamali hanya berlaku di lingkungan masyarakat Kampung Naga saja, kalau di luar mah terserah.

Kecap pamali yang diungkapkan terkait dengan kehidupan masyarakat Kampung Naga dalam melestarikan alamnya yakni "pamali asup ka leweng larangan" (masuk ke hutan larangan). Maksud dari kecap pamali tersebut adalah bahwa siapa pun dilarang masuk ke dalam hutan larangan. Hutan larangan sangat dikeramatkan oleh masyarakat Kampung Naga. Hal ini muncul pada perilaku masyarakat tersebut yang tidak berani masuk ke dalam hutan larangan, bahkan mengambil ranting yang sudah jatuh terbawa aliran sungai.

Maknanya dari kecap pamali masuk ke hutan larangan yakni supaya hutan tetap asri dan lestari sehingga dapat memberikan manfaat yang besar guna kehidupan Masyarakat Kampung Naga. Dalam pelaksanaannya pamali merupakan tuntunan yang paling penting untuk melestarikan kehidupan manusia bersama alam.
Penerapan kecap pamali di atas mengandung nilai ekologis di mana ada suatu hal yang baik terkait hubungan manusia dengan alam di sekitarnya (Istiawati, 2016; Estiyani, n.d.; Fitrida \& Misnah, 2019; Herbowo, 2020; Lestari, 2020; Supriatna, $2020 \mathrm{Ed})$.

Nilai guna dari kajian kecap pamali pada masyarakat Kampung Naga dapat dijadikan landasan dalam penguatan nilai ekologis bagi siswa Sekolah Dasar. Dimana siswa diberikan penguatan penyadaran tentang manfaat hubungan yang baik antara manusia dengan alam disekitarnya.

Pengembangan nilai ekologis ini dilakukan melalui proses pembelajaran yang menggunakan sumber belajar dari budaya lokal masyarakat tradisi (Holilah, 2015). Budaya lokal seperti yang terdapat di Kampung Naga ini memiliki nilai yang amat tinggi untuk diangkat oleh masyarakat modern pada masa kini yang dihadapkan pada degradasi moral. Budaya local ini dapat diterapkan pada kehidupan masyarakat modern seperti harus hati-hati dalam melakukan sesuatu, harus mengikuti normanorma yang ada disekitar lingkungan agar lingkungan kita tetap terjaga. Dari tradisi ini dapat dijadikan sumber belajar bagi siswa sekolah dasar. Tradisi kecap pamali ini dapat dijadikan landasan pendidikan karakter peduli lingkungan. Dengan pembelajaran karakter peduli lingkungan ini, diharapkan siswa dapat memiliki sikap dan perilaku yang selalu berupaya untuk dapat mencegah serta 
mengurangi kerusakan alam sekitarnya, serta dapat mengembangkan upaya-upaya untuk memperbaiki kerusakan alam yang sudah terjadi. Siswa juga harus diajarkan untuk memiliki rasa hormat dan mencintai terhadap lingkungan alam yang menjadi bagian tidak terpisahkan dari kehidupan umat manusia.

\section{KESIMPULAN}

Masyarakat Kampung Naga menjadikan kecap pamali sebagai papagon hirup (pegangan hidup) dalam menjalani kehidupan bermasyarakat. Kecap Pamali merupakan suatu legitimasi kata yang berisi larangan-larangan bagi masyarakat Kampung Naga yang dipahami serta ditaati secara turun temurun sebagai kesadaran social yang tulus, tanpa ancaman serta tanpa sanksi yang tertulis.

Dari kecap pamali tersebut mengandung nilai ekologis yang sangat bermanfaat dalam menjaga kelestarian hutan. Sehingga dapat dijadikan landasan dalam penguatan nilai ekologis bagi siswa Sekolah Dasar.

\section{DAFTAR PUSTAKA}

Apiyanti, S., Kosasih, D., \& Isnendes, R. (2015). Pamali Dina Kakandungan Nu Aya Di De'sa Jayagiri, Pikeun Bahan Pangajaran Maca Artikel Budaya. 3(3), 1-9.

As'ari, R., \& Hendriawan, N. (2016). Kajian Nilai Kearifan Lokal Masyarakat Adat. 472-486.
Danadibrata, R. . (2006). Kamus Bahasa Sunda. PT Kiblat Buku Utama.

Elfan Fanhas Fatwa Khomaeny, D. (2020). Indonesian Parenting (N. Hamzah (ed.)). Edu Publisher, 2020.

Estiyani, L. (n.d.). Nilai-nilai Ekologi Dalam Pada Cerita Rakyat Banyubiru Desa Sumber Rejo Kecamatan Winongan Kabupaten Pasuruan.

Febriana, R. (2019). Aktualisasi Nilai-nilai Kemandirian Dalam Membentuk Karakter Mandiri Siswa. 8(1), 577-582. https://doi.org/10.29313/tjpi.v8i1.4 575

Fitrida, \& Misnah. (2019). Implementasi Nilainilai Budaya Kearifan Ekologis Masyarakat Etnik Kaili di Donggala dalam Pembelajaran IPS di SMPN 4 Tanantovea Provinsi Sulawesi Tengah. 7(3), 103-110.

Herbowo, N. A. S. (2020). Kajian Ekologi Sastra Berbasis Nilai Kearifan Lokal Dalam Cerpen "Orang Bunian” Karya Gus TF Sakai. 7(1), 63-75. https://doi.org/10.15408/dialektika. v7i1.13887

Holilah, Mina. (2015). Kearifan Ekologis Budaya Lokal Masyarakat Adat Cigugur sebagai Sumber Belajar IPS. Jurnal Pendidikan Ilmu Sosial, 24(2), 163-179. Istiawati, N. F. (2016). Nilai-nilai Kearifan Ekologis Masyarakat Adat Krui Sebagai Alternatif Sumber Belajar IPS SD-SMP Di Pesisir Barat Lampung. 8(2), 173186. 
Lestari, A. (2020). Implikasi Nilai-nilai Ekologis Dalam Teori Kosmologi Ikhwan Al Safa. Diajukan.

Moleong, Lexy. (2002). Metode Penelitian

Kualitatif, Bandung: Remaja Rosdakarya.

Mustapa, H. (2010). Adat Istiadat Sunda. PT Alumni.

Nurdiansah, N. (2017). Pedagogi Jurnal Penelitian Pendidikan Volume 04 No 01 Mei 2017. 04(01), 59-69.

Permasih, D., Koswara, D., \& Kosasih, D. (2014). Aje'n Atikan Dina Folklor Aspek Kapamalian Anu Aya Di Desa Tanjungwangi Kecamatan Cicale'ngka Kabupaten Bandung ( Tilikan Semiotik). 1-13.

Rachmawati, Y. (2017). Parenting Tradition in Sundanese Culture in West Java-Indonesia (1st ed.). Pustaka Matahari.

Satjadibrata, R. (1948). Kamus Bahasa Sunda. Bale Poestaka.

Supriatna, M. (2020). Pendidikan Berbasis Etnik. Tulungagung: Akademi Pustaka.

Syafiuddin, M. (2020). Globalization In Islamic Education ( Internalization Strategy Of Local Values In Islamic Globalization Era). 9(1), 31-41.

Widiastuti, H. (2015). Pamali Dalam Kebidupan Masyarakat Kecamatan Cigugur Kabupaten Kuningan (Kajian Semiotik dan Etnopedagogi). Lokabasa, 6(1), 71-78. https://doi.org/10.17509/jlb.v6i1.31 49 
